\title{
A Síria como ator na Guerra Civil Libanesa: motivações e efeitos da intervenção de uma terceira parte na resolução de conflitos
}

\author{
Syria as an actor in Lebanese Civil War: \\ motivations and effects of the intervention \\ of a third party in conflict resolution
}

\section{MARCOS ALAN S. V. FERREIRA VLADEMIR MONTEIRO DOS SANTOS}

\section{INTRODUÇÃO}

O presente artigo propõe-se a examinar o papel da Síria na Guerra Civil Libanesa, em especial no período que compreende os anos de 1975 e 1976. O objetivo consiste em analisar essa atuação à luz da literatura de resolução conflitos sobre a intervenção de uma terceira parte no processo de resolução. Particularmente, será dada ênfase às motivações e aos efeitos da intervenção síria sobre a evolução do conflito libanês.

Desde seu processo de independência, iniciado em 1941 e plenamente reconhecido em 1943, o Líbano teve um arranjo político fragilizado pela governabilidade compartilhada entre os grupos religiosos do país. O país tem uma configuração governamental ímpar, na qual os cargos de primeiro-ministro, presidente e porta-voz do parlamento são obrigatoriamente ocupados, respectivamente, por um cristão maronita, um muçulmano sunita e um muçulmano xiita. Nos anos 1970, o aumento do fluxo imigratório de palestinos altera a demografia do país e, consequentemente, traz consi-

\footnotetext{
Marcos Alan S. V. Ferreira - Doutor em Ciência Política pela Unicamp (2010) e Mestre em Relações Internacionais. Programa Santiago Dantas (Unesp/Unicamp/PUC-SP) (2006). Como Pesquisador/ Professor Visitante, esteve na Universidade de Manchester (Reino Unido, 2018 e 2019), Universidade de Uppsala (Suécia, 2014), na Universidade de Vechta (Alemanha, 2017 e 2019) e na Universidade Núr (Bolívia, 2018).

Vlademir Monteiro dos Santos - Mestrando em Ciência Política e Relações Internacionais na Universidade Federal da Paraíba. Membro do Grupo de Pesquisa em Estudos Estratégicos e Segurança Internacional (GEESI).
} 
go tensões pontuais entre os grupos religiosos majoritários. Rapidamente, estas tensões escalam para massacres entre os grupos religiosos, gerando em seguida uma guerra civil com atores domésticos e internacionais diversos que duraria 16 anos.

Não obstante seu caráter doméstico, uma guerra civil dificilmente se confina apenas ao território do Estado em convulsão. Foi exatamente este quadro que seria visto na guerra civil libanesa. A instabilidade engendrada localmente transformou-se em uma fonte de perturbações que atingiram o plano regional. Essas ramificações fazem desse tipo de conflito, conforme salienta Kathman (2011, 850), "eventos internacionais” e, em virtude dessa externalidade, o envolvimento de agentes estrangeiros torna-se quase inevitável:

a comunidade internacional raramente trata as guerras civis como um problema estritamente interno. Estados e organizações intergovernamentais se envolvem nessas disputas de várias formas, tanto humanitária e puramente interesseira (Sawyer et al. 2015, 1.175).

Frente a este contexto, nosso exame do papel da Síria na guerra civil do país vizinho organiza-se em quatro partes. A primeira estabelece o referencial teórico que fundamenta a análise do envolvimento da Síria na contenda libanesa. O foco é abordar o que diz a literatura de resolução e gerenciameto de conflitos sobre as motivações e os efeitos de uma terceira parte na evolução de um conflito doméstico. A segunda, usando o modelo da penetração de Encarnation et. al. (1990), define as fases da atuação síria na guerra em estudo. Então são exploradas as razões pelos quais o regime de Damasco decidiu assumir o papel de terceira parte. Na última, com base em um estudo de Cobertta e Melin (2017), analisa-se os instrumentos usados pela Síria para gerenciar o conflito e como eles determinam sua evolução. Por fim, são apresentadas as considerações finais. No tocante à metodologia, o artigo consiste em uma pesquisa bibliográfica, orientada por uma abordagem qualitativa e estruturada em um estudo de caso. Além disso, serão empregadas predominantemente fontes secundárias.

\section{CONFLITOS DOMÉSTICOS E A INTERVENÇÃO DE UMA TERCEIRA PARTE}

A intervenção de um agente externo imprime sérios impactos sobre o fenômeno do conflito armado, a depender da maneira como esse ator age. Assim, na situação em que ele opere e empregue os meios à sua disposição de modo a fazer as hostilidades cessarem ou impelir os grupos beligerantes a negociar, seu comportamento corresponde ao que Sawyer et al. (2015) 
designam como inibidor de conflito. Contudo, caso ele alie-se a uma facção, seja governo ou rebeldes, sua conduta enquadra-se na de promotor do conflito. Essa dicotomia, todavia, contrasta com o argumento elaborado por Regan (1996; 2002) - e difundido na literatura de gerenciamento de conflito - de que a intervenção visa primariamente colocar um fim à belicosidade em curso. Nas palavras do autor,

os interesses do interventor giram em torno de assegurar estabilidade política numa região específica do globo; um modo de facilitar isso é ajudar a conter a violência militar - seja orquestrando um cessar-fogo ou facilitando a derrota do grupo opositor. É assumido que a terceira parte não intervém para exacerbar ou prolongar a luta (Regan 1996, 340).

Tanto a visão de que a terceira parte age como atenuador quanto a de que ela é um agravador do problema encontram respaldo na literatura. Aydin et al. (2009) indicam uma série de trabalhos que apontam as consequências negativas da intervenção sobre guerras internas. Entre os autores citados, Lindsay e Enterline (2000), com bases nos dados da plataforma Correlates of War, detectam a tendência desse tipo de ação arrastar a duração de guerras civis. Por sua vez, Regan (2000) afirma que, mesmo nas ocasiões em que a finalidade é, de fato, a interrupção da violência, ela não se mostra um instrumento eficiente. Esses e os demais estudos (Regan 2002; Elbadawi and Sambanis 2000; Collier et al. 2003) convergem à mesma conclusão: esse expediente é o fator responsável por prologar o conflito. Em oposição a essa visão, outras pesquisas (Doyle and Sambanis 2000; Walter 2002) evidenciam as contribuições do interventor no processo de resolução. Nesse sentido, num cenário em que se obteve o mínimo de paz (negativa), ele se alça à condição de peça chave — senão, imprescindível — em evitar que governo e insurgentes coloquem as mãos em armas novamente. Por exemplo, Fortna (2004) defende que as características de uma missão de paz externa são decisivas na estabilidade nos pós-guerra. Merece também destaque seu papel na implementação dos acordos de paz. Ao assumirem-se fiadores destes, esses atores podem determinar se compromissos assumidos continuem no papel ou ganhem forma na realidade. Em suma, há fortes indícios mostrando que a presença de uma terceira parte, embora não seja uma condição necessária, revela-se um fator influente na consolidação da estabilidade pós-conflito.

Por seu caráter ex post facto, as análises podem apresentar a intervenção como se fosse a primeira resposta e a mais óbvia adotada pelos agentes externos em reação a um conflito. No entanto, segundo Encarnation et al. (1990, apud Ramsbothan et al. 2005), o envolvimento da terceira parte 
não se efetua de maneira imediata, mas sim gradativa. Ilustrado através de um espectro, o modelo desses estudiosos conteria um extremo em que o potencial interventor está aquém da guerra e, no outro, totalmente imerso. Entre esses dois polos, situariam-se as posições intermediárias. Ao abandono da passividade, seguiria uma postura engajada, entretanto mais restrita (low profile), que, por sua vez, daria lugar ao papel mais de influenciador do que de protagonista.

Dentro deste debate teórico, é crucial abordar dois pontos: as causas e os efeitos da intervenção sobre os resultados da guerra civil. Ambas as problemáticas, junto com os efeitos sobre a duração dos conflitos domésticos, formam a tríada em torno da qual a agenda de pesquisa sobre intervenção tem se desenvolvido (Balch-Lindsay et al. 2008). Porém, conforme já mencionado e para melhor servir a seu escopo, este trabalho só focará nas duas questões iniciais. A primeira discussão diz respeito às condições em que um agente externo se envolve. Balch-Lindsay et al. (2008, 348) encontram uma gama tão ampla quanto possível de respostas: Suhrke e Noble (1977) baseiam-se em estudos de casos para demonstrar que terceiros frequentemente intervêm em guerras étnicas civis por razões inteiramente exógenas às próprias guerras e, assim, as guerras civis são muitas vezes travadas contra um pano de fundo de múltiplos níveis de interesse, fidelidade e envolvimento de terceiros. Holl (1993) argumenta que os terceiros são mais propensos a entrar em guerras civis conforme esses conflitos se aproximam de término. Finalmente, a análise de Regan (2000) sugere que terceiros são menos propensos a intervir quando a intensidade de uma guerra civil é alta e mais propensos a intervir quando uma crise humanitária é iminente.

A despeito dessa diversidade de explicações, existe uma visão de que a atuação da terceira parte é suscitada pelo autointeresse. Ao analisar essa perspectiva estatocêntrica e realista, Kim (2015) lista o desejo de expandir sua influência, manipular a política de governo no pós-conflito e aumentar seus futuros interesses como alguns dos motivos dos interventores. Nesse cenário, com o intuito de ter seus anseios atendidos, a terceira parte busca manejar as estruturas de poder locais a seu favor, ou seja, ela avalia se pode extrair mais vantagens do status quo ante ou post bellum. Seu cálculo se define nas seguintes palavras: "os benefícios esperados da intervenção dependem do comportamento futuro ou da política do Estado alvo no pós-guerra, que é determinada pela liderança política e pelos sistemas políticos/ econômicos que aparecem após o conflito” (Kim 2015, 5). Não surpreende, por conseguinte, a constatação feita por alguns pesquisadores (Lemke and Regan 2004; Ross 2004; Gent 2007) de que as terceiras partes tendem a levar a cabo intervenções unilaterais em Estados que lhes são estrategicamente importantes e onde eles podem esperar futuros benefícios. 
A partir desses argumentos, observa-se que os fatores domésticos acabam adquirindo certo destaque, com alguns autores evidenciando que a intervenção, em determinados casos, opera em função da política interna:

Bueno de Mesquita e seus colegas (2003) argumentam que os líderes políticos motivados a maximizar suas chances de sobrevivência política tendem a se engajar em processos de construção nacional em outros países e a tentar controlar a política dos [Estados] alvos. Ao expandir a esfera de controle ou influência, [esses] líderes podem fornecer aos seus apoiadores domésticos e partes significativas da população mais bens públicos ou privados, como segurança nacional, acesso a recursos naturais e expansão dos mercados (Kim 2015, 5).

Também explorando a problemática sob a ótica do autointeresse, Kathman (2010; 2011) indica que as motivações da terceira parte podem ser divididas em razões oportunistas e razões securitárias. Essa classificação se sustenta na ideia de que as guerras civis oferecem tanto oportunidades quanto ameaças ao potencial interventor. Dessa maneira, quando seu objetivo é aproveitar-se da situação, ele se envolve para "pilhar recursos, enfraquecer um inimigo, afetar a mudança de regime ou melhorar o status geopolítico”. Todavia, se sua preocupação pauta-se pela redução de ameaças, ele age para diminuir a instabilidade e cessar as hostilidades. Embora as razões assinaladas pareçam altamente atrativas, Kathman (2010) faz uma ressalva importante: a intervenção é um empreendimento custoso, portanto, não basta ter a oportunidade é preciso disposição em fazê-lo e apresentar fortes motivações para tal:

Conquanto a oportunidade seja uma condição necessária para a intervenção, ela por si só não é suficiente. Dados os custos associados ao envolvimento em guerras civis, as possíveis terceiras partes devem ter uma atração sincera pela intervenção para justificar a exploração dessa oportunidade. Em outras palavras, os interesses de um terceiro em um conflito vizinho devem ser substanciais o suficiente para produzir uma disposição em intervir (Kathman 2010, 991).

De acordo com o autor, os países que compartilham fronteiras com o Estado corroído por contendas internas apresentam ambos os "requisitos" mencionados anteriormente para assumir o papel de interventor. Entretanto, ele contesta as explicações que os estudiosos costumam apontar. O principal alvo de sua crítica são as chamadas teorias de conexão, cuja base argumentativa reside nos dyadic links (ligações diádicas). Esses funcionariam como fatores impulsionadores da conduta do interventor: "uma terceira parte provavelmente intervirá quando existem conexões poderosas entre ela e o país enfrentando a guerra civil” (Kathman 2010, 991). 
Portanto, dado que a guerra civil perturba a normalidade dessa dinâmica, a intervenção visa a restaurá-la.

Passando para a segunda problemática, os estudos apontam — analogamente à análise dos motivos feita acima - uma multiplicidade de formas de como a terceira parte pode influenciar os resultados do conflito, ou, de um modo mais amplo, como a abordagem escolhida por ela interfere na trajetória e dinâmica do conflito. Balch-Lindsay et. al. (2008, 348) descrevem esse panorama diverso, mencionando alguns trabalhos, tais como o realizado por Zartman (1993), cuja conclusão é a de que beligerantes da guerra civil buscam o apoio de terceiros, não apenas para obter recursos e refúgio, mas também para conseguir leverage, tanto no campo de batalha quanto na mesa de negociações, uma condição a que ele se refere como "triangulação". Já Regan (1996, 2000), tendo como amostragem os conflitos internos pós-Segunda Guerra, infere que os terceiros são mais propensos a ter sucesso em suas intervenções em guerras civis quando recorrem a uma estratégia que mistura políticas econômicas e militares. Por fim, Mason, Weingarten e Fett (1999) chegam ao entendimento de que as intervenções de terceiros tornam menos provável uma solução negociada, exceto se essa intervenção ocorra uma vez que uma guerra civil se torne prolongada, quando a probabilidade de um acordo negociado aumenta.

Fora dos exemplos anteriores, outro estudo que merece destaque é o elaborado por Corbetta e Melin (2017). Com base na classificação concebida por Rosenau (1969), os atores enfatizam duas abordagens de intervenção: a mediação e o que eles chamam de joining behavior (comportamento de adesão). ${ }^{1}$ A primeira comporta uma conotação positiva, na medida que é considerada uma forma de gerenciamento de conflito, isto é, um instrumento para estabelecer a paz negativa; no entanto, sobre a última paira uma percepção não muito favorável, pois é tido como a principal impulsionadora da expansão do conflito. Ainda que não se deva desprezar o método adotado pelo interventor, o elemento central nesse contexto, segundo Corbetta e Melin (2017), trata-se de sua relação com os contendedores, a qual produz implicações significativas sobre o processo de gerenciamento do conflito. Em suma, nota-se que "os laços [entre os beligerantes e o agente externo] servem como um canal de informações e um motivador de ação, aumentando tanto a oferta quanto a demanda por envolvimento de terceiros" (Corbetta and Melin 2017, 3).

A literatura sobre resolução e gerenciamento de conflitos problematiza essas relações de dois modos: (1) como mecanismo de leverage, através do qual se "exerce influência sobre um ou ambos os disputantes, incentivando-os a resolver o conflito" (Corbetta and Melin 2017, 4). Portanto, leverage define-se em termos do poder e da autoridade da terceira parte 
em influenciar os combatentes. Observa-se que seu uso é impactante, visto que, com ele, é possível ao interventor elevar os custos aos beligerantes de rejeitar um acordo; aumentar os ganhos provenientes do comprometimento com as negociações; e prover ferramentas para assegurar o cumprimento dos acertos; (2) como mecanismo de definição de preferências, em que a terceira parte possui uma "afiliação assimétrica com um dos combatentes" (Corbetta and Melin 2017,4). Sob essas circunstâncias, o ator externo opta por aliar-se a um dos lados, a fim de resolver o conflito de modo a favorecê-lo.

Não existe um consenso na literatura a respeito da eficiência do comportamento parcial na resolução dos conflitos, ao passo que a temática suscita intensos debates. Os que endossam esse tipo de postura elencam vantagens como: [1] um mediador não neutro tem mais credibilidade aos olhos do disputante que ele defende e tem menos incentivos para deturpar a posição da parte favorecida, tornando-se mais confiável também para o lado menos beneficiado (Kydd 2003 apud Corbetta e Melin 2017); [2] esses gerenciadores produzem acordos duradouros porque eles têm interesses nos resultados e, portanto, são motivados a aplicar o máximo de leverage sobre os combatentes, enquanto os mediadores neutros estão empenhados principalmente em acabar com o conflito e gerar acordos mais rápidos, mas de menor qualidade; [3] terceiras partes parciais, e especialmente as mais poderosas, têm mais motivos para (a) expandir o espaço de barganha disponível e (b) coagir um relutante litigante a reduzir suas demandas e aceitar um acordo que ele normalmente rejeitaria (Favretto 2009; Yuen 2009 apud Corbetta e Melin 2017).

Embora pareça que o agente externo utilize um desses meios em detrimento do outro, Cobertta e Melin (2017) demonstram que a realidade nem sempre segue essa tendência. Pelo contrário, ele também emprega o que os atores designam técnica dual - uma combinação de instrumentos neutros e parciais de gerenciamento. O que determina a adoção dessa estratégia é o desenrolar de seu envolvimento com os beligerantes. Havendo relações positivas entre eles, a terceira parte tende a ser um mediador imparcial. Porém, quando se instala algum tipo de assimetria entre eles - por exemplo, o potencial interventor possui mais relações com um lado do que com o outro - torna-se provável que a terceira parte busque adentrar o conflito a fim de favorecer seu protegido. Em virtude disso, ela dará preferência à técnica dual, aplicando seu leverage — sobretudo contra a facção à qual se opõe - para induzir a resolução não violenta da contenda. No entanto, quando surgem incompatibilidades de tal maneira que os interesses não convergem, os meios diplomáticos e coercitivos são colocados de lado e o país interventor adota o comportamento de adesão. Em outras palavras, 
ele se aliena totalmente de um dos beligerantes e passa a apoiar o outro em sua luta para derrotar aquele.

Nota-se que Coberta e Melin (2017) lidam com a problemática das três faces do poder, embora essa não se encontre abordada explicitamente. Segundo Ramsbotham et al. (2005), tal categorização foi introduzida por Boulding (1989) e contrapõe-se ao binômio convencional soft power e hard power. Enquanto este último seria o poder de ameaça, o primeiro se dividirá em duas dimensões: "poder de troca, associado à barganha e ao comprometimento ('faça o que eu quiser e eu farei o que você quer'), e poder integrador, associado à persuasão e à resolução de problema transformativa de longo prazo (“juntos podemos fazer algo que é melhor para nós dois')” (Ramsbotham et al. 2005, 20). Aplicando tal classificação ao trabalho de Coberta e Melin, esses elementos, na ordem que foram expostos, permeariam, respectivamente, o joining o leverage e a mediação neutra. Na realidade, essa divisão não é tão fixa, dado que, por exemplo, o hard power pode ser instrumentalizado no exercício do leverage e não exclusivamente como um recurso de joining, e até a mediação, mesmo quando neutra, pode ser valer de elementos coercitivos, o que corresponderia à mediação com músculos.

Como veremos na seção seguinte, o envolvimento sírio na Guerra Civil do Líbano não fora uniforme, tendo variado em termos de ferramentas e intensidade. As fases deste envolvimento à luz da literatura aqui explorada serão examinadas a seguir.

\section{AS FASES DO ENVOLVIMENTO: DA ABORDAGEM LOW PROFILE A PLAYER INDISPENSÁVEL}

Pode-se dizer que a Síria seguiu na Guerra Civil Libanesa aquele modelo de participação de terceira parte elaborado por Encarnation et al. (1990). Ou seja, ela penetrou gradualmente no conflito até assumir um papel protagonista nessa dinâmica. Entretanto, é válido lembrar que sua ingerência nos assuntos internos do Líbano antecede o irrompimento da luta armada. Na crise libanesa de 1958, marcada pela invasão dos marines norte-americanos, Damasco deu assistência militar e logística aos nacionalistas mulçumanos, além de promover uma guerra de propaganda, por meio de sua rádio oficial, contra o governo em Beirute. Nos anos 1960, os incumbentes sírios buscaram obter algum tipo de controle sobre as guerrilhas palestinas que operavam em território libanês. E, na década seguinte, ocorreu uma aproximação entre a elite alauita do regime Assad e as comunidades xiitas libanesas. Fora isso, houve também uma tentativa de normalização das relações diplomáticas (Dawisha 1980; Weinberger 1986). 
Weinberger (1986) identifica três fases no engajamento: a mediadora, na qual os sírios desempenham uma atuação marginal; a intervenção indireta, onde exercem maior influência; e por fim, a intervenção militar, que os consagra como um player decisivo. Na primeira etapa, o regime Assad recorreu aos meios diplomáticos. A preferência por tal mecanismo se explica por sua aversão ao risco. Segundo Weinberger $(1986,12)$,

a Síria esperava e preferia alcançar seus objetivos no Líbano sem recorrer à intervenção [militar]. Em um processo de tomada de decisão cauteloso e incremental, [seus] líderes procuraram restringir o nível de comprometimento do país a estratégias que envolvessem os menores custos e riscos possíveis.

Outro aspecto dessa fase trata-se do caráter low profile adquirido pela abordagem: "durante os primeiros meses [da guerra], o papel da Síria era discreto, muitas vezes não reconhecido, e geralmente feito nos bastidores" (Weinberger 1986, 143).

A etapa intermediária do envolvimento sírio testemunha um desvio da postura, aparentemente neutra, característica da fase anterior. A despeito disso, Damasco mostrou-se reticente em tomar grandes riscos e essa preocupação também permeia a escolha da estratégia de atuação nesse cenário. Ao invés do envio de tropas do exército nacional, o governo opta por instrumentalizar as guerrilhas palestinas estacionadas em solo sírio em favor de seus interesses. Assim, no início de 1976, sob suas ordens, 3.500 homens da brigada Yamurk juntaram-se aos combatentes do Exército de Libertação da Palestina (ELP), no cenário libanês. Na leitura de Weinberger (1986), o resultado disso é que o governo Assad estabelece uma relação de clientelismo com a resistência palestina, sendo esta seu proxy e ele, o patrono dela. Ao fim dessa fase, a maior parte do Líbano estava sob ocupação dos paramilitares palestinos, o que significava, na prática, que o país estava sob jugo indireto da Síria.

O terceiro estágio cimentou o aprofundamento da atuação de Damasco, O desenvolvimento responsável por isso foi a intervenção militar, levada a cabo em maio de 1976. Pela primeira vez, a Síria estacionou tropas de seu exército em solo libanês, cuja missão era neutralizar as facções rebeldes e membros da resistência palestina, os quais haviam recomeçado a luta armada. Sua investida representa uma mudança de alinhamento, uma vez o governo agiu em prol do establishment, e também acarreta o abandono da abordagem diplomática. Percebe-se então uma reviravolta no papel dos sírios: eles deixam de desempenhar a função de mediador e assumem a de beligerante. Somente quando sua posição militar se torna incontestável eles voltam a considerar os meios não coercitivos, com o intuito de consolidar seus ganhos no campo de batalha. Assim, essa penetração conduz a 
Síria para o centro do conflito, transformando-a num ator imprescindível na resolução da Guerra Civil Libanesa.

A operação não recebeu respaldo ao nível regional. Egito, Iraque e Arábia Saudita se mostraram veementemente opostos à ofensiva - inclusive, os sauditas, como meio de expressar sua insatisfação, retiraram suas tropas da fronteira entre Síria e Israel, estacionadas ali desde a Guerra do Yom Kippur (1973). Outros reforçaram seus laços com as facções libanesas e a Resistência Palestina a fim de minar os objetivos sírios. Em razão das discordâncias, Damasco teve dificuldades no front diplomático, essencial para abrandar a resistência do mundo árabe e eventualmente conseguir o apoio dele à intervenção. Quando sugeriu a realização de um encontro com Egito, Arábia Saudita e Kuait para pautar a resolução da crise libanesa, a proposta não foi aceita, pois esses países defendiam que o Líbano e a Jordânia também fossem convidados. Apesar da rejeição, Assad obteve ganhos importantes na conferência, tais como a legitimidade à ocupação. Potências regionais como o Egito, capitaneado por Anwar Sadat, acabaram alinhando-se aos interesses sírios (Deeb 2003).

\section{POR QUE INTERVIR? AS MOTIVAÇÕES DO ENGAJAMENTO SÍRIO}

Como anteriormente demonstrado, na literatura prevalece a tese de que uma terceira parte se envolve em uma guerra civil menos por razões humanitárias do que pelo autointeresse. O caso da Síria, ao que tudo indica, fornece evidências para endossá-la. Porém, mesmo convergindo com a ideia de que a conduta de Damasco se guiava, essencialmente, pela busca de vantagens próprias, as leituras a respeito apresentam explicações variadas. Alguns trabalhos destacam a dinâmica doméstica como um fator propulsor do envolvimento sírio na contenda libanesa. Seguindo essa perspectiva, Lawson (1984) propõe que a intervenção foi instrumentalizada pela coalizão dominante para conter a oposição de seus adversários. A manobra se revelava atraente, porque poderia oferecer recursos extras, que fortaleceriam a posição do governo no cenário político interno, diante de um esgotamento dos recursos domésticos.

Para o autor, três recursos despertaram o interesse do regime sírio. $\mathrm{O}$ primeiro dele é o capital das instituições financeiras libanesas, do qual a economia síria, sobretudo o setor privado, tinha uma enorme dependência. Todavia, a guerra civil interrompera seu fluxo, além de criar um excesso de liquidez, em virtude da estagnação da atividade econômica interna do Líbano. O resultado disso é que Beirute tornou-se um centro financeiro inerte, com um imenso montante de crédito paralisado. Portanto, a continuidade do conflito a curto ou longo prazo só geraria mais dificuldades 
econômicas para Damasco. Por outro lado, a intervenção, "ao dar um fim à violência, [criaria] condições em que as atividades financeiras poderiam voltar ao normal, [com] o capital libanês novamente disponível para as empresas sírias" (Lawson 1984, 475).

O segundo recurso envolve a importação de bens de consumo. Tal como o setor financeiro, a indústria leve do Líbano foi afetada pela beligerância e, em decorrência disso, suas exportações para a Síria também sofreram impactos. A suspensão das trocas comerciais teve consequências negativas para a balança de pagamentos síria, cujo déficit ampliou-se, visto que, para atender à demanda interna, o governo recorreu aos mercados ocidentais. Esse quadro evidencia a dependência de Damasco em relação à indústria de bens leves libanesa. Esta desempenhava uma função complementar na estrutura produtiva de seu vizinho, cujo parque se concentrava na fabricação de itens pesados (Lawson 1984).

Por fim, o terceiro recurso se trata do acesso ao porto de Beirute, considerado o maior e mais eficiente da região do Levante. Essa era também questão sensível, porque o confronto no Líbano afetou a comunicação marítima da Síria com o mundo e, naturalmente, seu comércio exterior. Dada a impossibilidade de ter contato com Beirute, os portos de Lataquia e Tartus se tornaram os principais entrepostos; no entanto, eles não conseguiam dar conta da demanda - os atrasos no embarque e desembarque de mercadorias passaram a ser a regra. Os exportadores ainda tiveram que lidar com o aumento nos custos das transações resultantes do desvio do comércio para o norte do país. Além disso, a conexão com o Beirute tinha um valor estratégico, porque tanto Lataquia quanto Tartus abrigavam setores que faziam oposição ao governo (Lawson 1984).

Nota-se que a restauração da ordem no Líbano, através da coerção, era indispensável aos interesses econômicos e políticos da Síria. Nas palavras de Lawson (1984, 476), "Beirute [...] representava não apenas um 'emprestador de última instância’ e uma fonte de bens manufaturados leves para a coalizão governante [...], mas também uma linha de transporte e comunicação que era econômica e politicamente essencial ao regime”. Pode-se, portanto, inferir que a operação ocorreu em função de razões oportunistas. Ou seja, a coalizão governante encontrou no conflito circunstâncias que poderiam melhorar seu bem-estar. Ao mesmo tempo, a análise de Lawson contraria a avaliação de Kathman sobre os dyadic links. Conforme ficou explicitado, a Síria foi impactada com a desestabilização dos laços com o Líbano e normalizá-lo tornou-se convenientes. Em resumo, os dyadic links influenciaram a decisão de intervir.

Afastando-se do foco doméstico, Hinnebusch $(1986,1998)$ atribui o envolvimento sírio a razões securitárias. Seu argumento é de que o conflito 
permitiria Israel ampliar sua presença no Líbano. Sendo assim, o temor de dividir fronteiras com o Estado judeu impeliu o regime Assad a atuar como terceira parte. Nas palavras do próprio autor, o motivo imediato da intervenção “[ …] foi a grave ameaça à segurança [decorrente da] perspectiva de que a guerra civil e o desmembramento [do Líbano] abririam as portas para a penetração israelense" (Hinnebusch 1998, 140). As apreensões do governo sírio decorriam da evolução da própria contenda. Com a resistência palestina tomando o controle do território libanês, os grupos cristãos buscaram cooptar Tel Aviv a entrar na batalha em seu favor, pois havia o receio de que uma dominação muçulmana engendraria uma vingança sectária contra eles. Diante da possibilidade de uma interferência israelense e uma consequente balcanização do Líbano, as autoridades em Damasco pressionaram o ELP a recuar e aceitar seus planos diplomáticos. Apesar das relações de clientelismo entre ambos, os palestinos se recusaram a acatar tais ordens e, em reação a isso, as tropas sírias marcharam para o Líbano.

Hinnebusch (1998) consegue demostrar o peso das preocupações securitárias no cálculo dos dirigentes sírios, para os quais, de acordo com a leitura do autor, as ameaças a seu país colocavam-se acima de que quaisquer alinhamentos. Portanto, vista a partir do prisma realista, a intervenção almejava primordialmente evitar riscos maiores à sobrevivência nacional. Na mentalidade dos interventores, a consolidação da posição palestina daria aos israelenses uma justificativa para este concretizar seu projeto de ampliar suas fronteiras, implicando em graves consequências no teatro militar. Reforçando essa perspectiva, Dawisha (1978, 136-137) salienta que a percepção expansionista do establishment no tocante às ações de Israel fora o substrato da decisão de invadir o Líbano, pois:

O regime estava convencido de que uma divisão do Líbano daria a Israel o pretexto para entrar no sul do Líbano e ocupar a área até o rio Litani. A ocupação israelense, com certeza, aumentaria consideravelmente a vulnerabilidade estratégica da Síria ao fornecer a Israel uma nova frente em qualquer confronto futuro. Os israelenses poderiam atacar os sírios na região de Golã, enquanto realizavam um rápido ataque a Damasco através do altamente exposto vale de Beqa no Líbano, e os sírios dificilmente são capazes de lutar contra Israel em dois fronts.

\section{INSTRUMENTOS E EFEITOS SOBRE A EVOLUÇÃO DA GUERRA}

Conforme exposto ao se abordar as fases de seu envolvimento, a Síria afetou a trajetória da guerra libanesa de formas variadas, em reflexo aos instrumentos empregados. Semelhante à análise de Cobertta e Merlin 
(2017), um fator decisivo nisso foi suas relações com os beligerantes, as quais tiveram um papel decisivo na escolha da mediação, da técnica dual ou do joining behaviour (comportamento de adesão) como abordagem de engajamento.

\section{O uso dos meios diplomáticos}

Como descrito por Weinberger (1986), a etapa inicial de seu envolvimento caracterizou-se pelo uso de meios diplomáticos. Esse comportamento devia-se à credibilidade de que a Síria desfrutava perante os dois lados da guerra. Na verdade, tendo bom trânsito entre os grupos pró status quo e as lideranças anti-establishment, ela conseguia equilibrar suas relações com os dois lados, de modo que, em um dado momento, ambos lhe apelaram para atuar como mediador. Hinnebusch (1986) discorda dessa interpretação, e argumenta que os esforços diplomáticos constituíam uma dimensão da estratégia síria. Paralela e secretamente, o regime Assad adotava práticas não tão apartidárias, a exemplo do fornecimento de armamento às facções de esquerda e à resistência palestina. Para Deeb (2003, 10), ainda que parecessem contraditórias, essas ações tinha um propósito totalmente lógico: "enfraquecer o estado libanês e forçá-lo a buscar o apoio político do regime Assad e a considerá-lo com único e indispensável mediador e árbitro".

A despeito dessa ambiguidade, a assistência dada aos rebeldes não significava uma preferência por um dos beligerantes, e tal constatação é endossada pela ausência, nos planos de resolução esboçados por Damasco, de propostas para favorecer um deles em prejuízo do outro. Pelo contrário, defendia-se uma "perpetuação do sistema político libanês [existente], com apenas reformas institucionais pequenas" (Weinberger 1986, 141). Seale (1988) ressalta que o objetivo era obter concessões para os rebeldes dentro do arcabouço institucional já estabelecido, resultando numa acomodação das incompatibilidades que geraram o conflito. Na prática,

[os bons ofícios sírios eram] dirigidos a reviver instituições políticas libanesas imobilizadas. Quando isso se revelou difícil, a Síria fez várias tentativas de inovação institucional, patrocinando órgãos políticos interinos para resolver a crise e restaurar a ordem (Weinberger 1986, 142).

\section{A técnica dual em ação}

O recrudescimento da violência acarretou mudanças na estratégia de engajamento da Síria, levando-a fazer uso da técnica dual. O elemento de- 
sencadeador disso repousa nas assimetrias que se instalaram em suas relações com os grupos maronitas. As posições assumidas pelos líderes cristãos contrariaram os interesses de Damasco. Segundo O’Balance (1998), eles se mostravam descontentes e críticos com o Acordo do Cairo (1969), cujos termos conferiram respaldo jurídico à presença palestina em território libanês, além de serem intransigentes quanto a qualquer sugestão de alterar o Pacto Nacional (1943), o qual dava legitimidade a divisão de poder existente sob bases sectárias. Fora isso, as milícias cristãs empreenderam uma ofensiva militar contra as facções palestinas. Todas essas ações não podiam produzir outro resultado senão clivagens, visto que os objetivos do governo Assad, segundo seu ministro da informação, eram “1) evitar a partição do Líbano independentemente dos sacrifícios ou recursos que isso pudesse exigir; 2 ) estabelecer a segurança e a paz no Líbano; 3 ) proteger a resistência palestina" (Weinberger 1986, 141).

Particularmente, o que acentuou as divergências foram as suspeitas sobre os planos secessionistas dos cristãos (Hinnebusch 1986; Hudson 1978). Entre todos os futuros desenhados por Damasco para seu país vizinho, nenhum concebia um desmembramento dele. O Ministro dos Assuntos Exteriores da Síria, Abdul Halim Khaddam, descreveu a aversão a essa ideia com as seguintes palavras,

o Líbano era parte da Síria e nós o recuperaríamos se houvesse qualquer tentativa real de partição. [Portanto,] deve ficar claro que isso não significa apenas as quatro províncias e as áreas costeiras, mas também o Monte Líbano [habitado majoritariamente por cristãos]. Ou o Líbano permanece unido ou deve ser incorporado pela Síria (Deeb 2003, 13).

A rejeição a esse cenário expressava diretamente suas preocupações securitárias, já aludidas anteriormente. Um Estado de maioria cristão tornar-se-ia suscetível à penetração de Israel, que já prestava assistência militar aos militantes maronitas. Segundo Mitton (2017, 10), esse desfecho seria altamente atrativo aos interesses estratégicos de Tel Aviv: "a existência de uma considerável população cristã maronita no Líbano há muito sugeria aos líderes israelenses o potencial para um relacionamento especial e possível aliado em uma região hostil”. Em suma, a Síria teria um inimigo à sua porta.

Em conformidade com que já foi citado, no intuito de evitar que tal perspectiva se materializasse, o governo Assad recorreu a uma intervenção indireta através das milícias palestinas. Sua participação não se limitou ao âmbito estratégico, pois, segundo o relato de um comandante, ele "rearmou essas unidades [do Exército de Libertação da Palestina] e 
reforçou-as com artilharia pesada... e as assistiu com o fogo de sua artilharia por trás das fronteiras no Vale de Beqaa” (Deeb 2003, 14). A ofensiva infligiu várias derrotas às forças pró status quo, revertendo seus ganhos. A principal consequência manifesta-se na alteração da balança militar em prol do anti-establishment, que, por sua vez, afeta a evolução do conflito num quadro mais amplo.

Os desdobramentos posteriores ilustram como funcionou a aplicação da técnica dual. Ao impor mudanças na dinâmica do campo de batalha, o regime em Damasco conseguiu leverage para obter um resultado favorável a seus aliados na seara diplomática. Essa percepção é endossada pelo mesmo comandante citado acima, de acordo com o qual o objetivo dos ataques era "forçar o outro lado a aceitar o fim do combate e a submeter-se a iniciativa [diplomática] síria” (Deeb 2003, 14). Dito de outro modo, Assad usou os meios coercitivos para gerar pressão por uma resolução política. O primeiro resultado disso se concretizaria com um cessar fogo, costurado em janeiro de 1976 por uma missão diplomática envida à Beirute logo a seguir. Seu monitoramento caberia a um grupo de cinquenta oficiais militares sírios (O’Ballance 1998; Weinberger 1986).

O principal fruto dos bons ofícios dos sírios culminaria no Documento Constitucional. Esse programa significa uma mudança no curso de suas preferências, na medida em que estabelece reformas institucionais com o propósito de favorecer à maioria mulçumana, ao invés de ajustes pontuais como defendido na fase da mediação. Concretamente, sua implementação imprimiria um reordenamento do poder político, mas preservando seu caráter sectário. Entre as reformas previstas, constavam:

representação parlamentar igualitária entre cristãos e muçulmanos [abolindo-se assim a fórmula 6:5]; mais poderes ao primeiro-ministro sunita que deveria ser eleito pelo legislativo em vez de indicado pelo presidente [cargo atribuído a um maronita]; fim das restrições sectárias ao acesso para postos do alto escalão no serviço público (Seale 1988, 277).

O’Ballance (1998) observa que Assad não agiu por outra causa senão a dos interesses de seu país. Assim, apesar das concessões à população muçulmana, ele evitou a dominação dela sobre os setores cristãos com o intuito de ter margem para manipular ambos de acordo com seus cálculos políticos. Resumidamente, "muito preferível para a Síria a um Líbano radicalizado era uma situação na qual poderia desempenhar o papel de equilibrador entre duas comunidades rivais e, portanto, exercer a hegemonia” (Hinnebusch 1986, 6). 


\section{Adotando um comportamento de adesão}

Não obstante os ganhos com a técnica dual, a Síria viu-se obrigada a renunciar a ela e executar um comportamento de adesão. Novamente, a explicação dessa guinada não pode prescindir de uma análise de suas relações com as partes do conflito. O ponto de partida é o Documento Constitucional, que paradoxalmente semeara discórdias entre Damasco e seus aliados. Enquanto a iniciativa ganhou o respaldo das lideranças cristãs, as milícias palestinas e a facção rebelde Movimento Nacional Libanês (MNL) encabeçada por Kamal Jumblatt, eram totalmente contra (Deeb 2003; O'Ballance 1998).

Embora tenha obtido ganhos a partir da manobra síria envolvendo as guerrilhas palestinas, Jumblatt tinha ressalvas quanto à ampliação do papel de Damasco nos assuntos internos do Líbano. A fonte de sua oposição reside justamente no Documento Constitucional. Para Deeb (2003, 15) ele "era crítico e insatisfeito com [a proposta], porque, se implementada, [...] acima de tudo, a Síria se beneficiaria mais". Tampouco ela atenderia suas aspirações políticas, haja vista que, além de preservar os privilégios dos maronitas, manteria o teor sectário das estruturas de poder. Dessa maneira, não poderia chegar à "presidência que era reservada apenas aos maronitas. Para governar o Líbano, como pretendia, ele tinha que esmagar o sistema confessional, mas isso significava esmagar os cristãos ou, ao menos, subjugá-los" (Seale 1988, 281). Um diálogo entre ele e o presidente Assad, num encontro de março de 1976, exemplifica seu posicionamento: “ [Quando este o perguntou $]$ 'Por que você continua escalando a luta? As reformas do Documento Constitucional te dão $95 \%$ do que você quer. $\mathrm{O}$ que mais você busca?’ Ele respondeu que queria se livrar dos cristãos que 'tem nos dominado há 140 anos”' (Seale 1988, 281).

Outros desdobramentos expuseram ainda mais o quão antagônicos se tornam os interesses dos sírios e dos rebeldes. Um exemplo disso foi um motim nas forças armadas libanesas. Incentivados por Jamblatt e a resistência palestina, soldados e oficiais de origem muçulmana desertaram, formando o Exército Árabe do Líbano (Deeb 2003). Na avaliação das autoridades em Damasco, a insurreição almejava sabotar seus esforços de paz, criando mais tensões através da desintegração das instituições militares. Na ausência de um aparato para manter a lei e a ordem, não prevaleceria outro cenário senão o estado da natureza no estilo hobbesiano (Weinberger 1986). Tendo esse pano de fundo, o comandante do MLN, junto com a Organização de Libertação da Palestina, lançou uma ofensiva contra os redutos maronitas. Na visão de Deeb (2003), o debacle de um dos instrumentos da dominação cristã criou a situação oportuna para aplicar 
o golpe de misericórdia contra ela. Em março de 1976, a violência armada voltou a dar o tom da paisagem libanesa.

Para Damasco, um Líbano governado por Jamblatt era tão inconcebível quanto um mini Estado maronita sob a influência israelense. Mais uma vez, o fator segurança pesara sobre os cálculos de suas lideranças. Por motivos diferentes, a vitória do MLN abriria caminho para a tão indesejada presença de Tel Aviv às fronteiras sírias. Seale $(1988,281)$ descreve suas preocupações assim: "Assad ficou horrorizado com a perspectiva de um Líbano radical e aventureiro em seu flanco, provocando Israel e alarmando o Ocidente por dar carta branca aos militantes palestinos". Jumblatt tornou-se tão recalcitrante com a opção militar que suas posições e de seu aliado tornaram-se irreconciliáveis. Ao declarar que "nós somos contra qualquer partido que insista em continuar o confronto" (Weinberger 1986, 198), Assad revela que as assimetrias se ampliaram ao ponto de o rompimento ser inevitável.

Essa ruptura conduziria a um joining behaviour. Tangivelmente, a Síria tomaria o lado dos cristãos maronitas e empreenderia uma intervenção militar em favor deles, em junho de 1976. Hinnebusch (1986, 6-7) atribui a decisão por um comportamento de adesão ao insucesso na aplicação de instrumentos dissuasórios, ou seja, "os sírios tentaram coagir seus aliados, a princípio cortando os suprimentos, depois despachando forças para o outro lado da fronteira e, finalmente, em junho de 1976, através de uma campanha multifacetada no Líbano, [visando] principalmente a mais intimidar do que derrotá-los". O evento que precipitou a invasão foi o ataque do Exército Árabe do Líbano a vilas maronitas, no norte. A população local então enviou telegramas a Assad pedindo que restaurasse a ordem e a lei. Desse clamor, o governo de Damasco tirou a justificativa pública para agir. No início de junho, tropas sírias avançaram pelo vale do Beca, liberando as áreas cristãs do cerco das forças rebeldes. (O’Ballance 1998; Seale 1988; Weinberger 1986).

A essa operação seguiu uma ofensiva maior contra as posições dos rebeldes. Estes, contraindo as expectativas da Síria, reagiram com forte resistência ao avanço de suas tropas. No entanto, os interventores conseguiram, ao fim de outubro de 1976, fazer a balança de forças, no campo de batalha, pender em prol deles e de seus novos aliados. Graças a essa reviravolta, as milícias cristãs, antes na defensiva, passaram ao ataque. Um dos reveses mais significativos impostos por eles foi a tomada do campo de refugiados Tall al-Za'tar nos subúrbios de Beirute. Da investida Assad colheu um ganho importante: a resistência palestina buscou uma conciliação com ele (Seale 1988; Weinberger 1986). 
Na perspectiva da evolução da guerra, a conjuntura que se estabeleceu on the ground proporcionou a Damasco condições para extrair mais ganhos na seara diplomática e, particularmente, confirmar seu status de árbitro do conflito. Esses desenvolvimentos se efetuaram na Conferência de Riad, na Arábia Saudita, ocorrida em outubro de 1976, sob os auspícios da Liga Árabe. O principal resultado do encontro foi o estabelecimento de uma missão de peacekeeping, a Força Árabe de Dissuasão (FAD). Seu mandato incluía as seguintes responsabilidades: "implementar de um cessar-fogo, auxiliar as autoridades libanesas no restabelecimento do controle sobre serviços públicos e instituições, e supervisionar a retirada de todas as forças armadas para as posições ocupadas antes de 13 de abril de 1975" (Thompson 2002, 76).

Thompson (2002) salienta que, embora arquitetada pelos sauditas com o intuito de frustrar a consolidação da Síria como terceira parte indispensável na contenda libanesa, a reunião acabou tendo o efeito contrário. $\mathrm{Na}$ falta de consenso sobre o tamanho da participação do país na FAD, o Kuait sugeriu que a decisão coubesse ao presidente libanês, que atribuiu aos sírios a tarefa de fornecer 25 mil dos 30 mil homens para a operação. Além de garantir a hegemonia militar síria, a ocasião foi instrumental na construção a posteriori da legitimidade da interferência. Ao dar às tropas de Assad a roupagem de missão de paz, a Liga Árabe revestiu de legalidade a presença delas no Líbano. Logo, podia-se alegar que elas agiam em nome de um organismo multilateral e do pan-arabismo. Nota-se ainda que os esforços focaram mais no gerenciamento do que na resolução do conflito, pois "reformas, sejam políticas ou sociais, nem sequer foram mencionadas nas resoluções da cúpula árabe, nem mesmo o documento constitucional patrocinado pelos sírios de fevereiro de 1976" (Deeb 2003, 29). Enfim, através da FDA, a presença miliar de Damasco ampliou-se, tirando dos rebeldes o controle de cidades importantes como Sídon e Trípoli. Apesar de eventuais episódios de violência, o caos hobbesiano cessara, e o Líbano voltou a ter o mínimo de normalidade, o que endossa a visão de que a terceira parte busca dar um fim às hostilidades e não as prolongar.

\section{CONSIDERAÇÕES FINAIS}

O presente trabalho buscou contribuir com um estudo de caso pontual sobre a intervenção de terceira parte em conflitos civis. De fato, a ideia aqui foi mostrar como o papel sírio no início da Guerra Civil do Líbano pode ser compreendido à luz da literatura corrente sobre resolução e gerenciamento de conflitos armados. Logo, buscou-se explorar e compreender as motivações e os efeitos do envolvimento de Damasco para a evolução do conflito no país vizinho. 
De todo modo, a aplicação desse referencial ao papel da Síria no conflito libanês permite elaborar as seguintes observações: primeiro, o envolvimento de atores externos em um conflito doméstico é quase inevitável. O que oscila é a intensidade e a profundidade da atuação. Do início ao fim do período em estudo (1975-1976), a presença do regime Assad na guerra libanesa fora uma constante, havendo poucas evidências para acreditar que Damasco não se envolveria. Por outro lado, seu comprometimento operou de forma gradual. Independentemente disso, a intervenção síria endossa a externalidade das guerras civis.

Segundo, a participação de uma terceira parte explica-se por razões variadas. É contraproducente apontar apenas um fator como causa. Devese admitir que algumas motivações acabam tendo preponderância, porém tantas outras influenciam a decisão de intervir. O caso da Síria só reforça a validade desse argumento. A análise feita neste artigo mostra que se pode atribuir a intervenção a considerações econômicas e securitárias, mas não exclusivamente a uma delas. $\mathrm{O}$ único denominador comum entre elas é o fato de atenderem ao autointeresse.

Por fim, a terceira parte afeta o curso de uma contenda doméstica. Nesse quesito, o aspecto crucial é a sincronia entre instrumentos de intervenção, desdobramentos on the ground e resultados obtidos e esperados. No caso sírio, no processo de beligerância em seu país vizinho, o governo mostrou certa flexibilidade no que diz respeito ao emprego de meios de intervenção. Essa variação devia-se ao quanto os resultados na seara diplomática ou no campo de batalha atendiam a seus interesses. Dessa maneira, ao avaliar se o status quo ante ou post bellum lhe servia, o regime em Damasco conseguia nortear as trajetórias da guerra, calibrando-as conforme seus interesses.

\section{REFERÊNCIAS}

Aydin, Aysegul et al. 2009. "Diplomatic interventions and civil war: a new dataset". Journal of Peace Research 46, no. 1 (January): 135-146. https://doi.org/10.1177\%2F0022343308098408

Balch-Lindsay, Dylan et al. 2008. "Third-party intervention and the civil war process". Journal of Peace Research 5, no. 3 (May): 345-363. https://doi. org/10.1177/0022343308088815

Beardsley, Kyle, and Kristian Gleditsch. 2004. "Nosy neighbors: third-party actors in Central American conflicts". Journal of Conflict Resolution 48, no. 3 (June): 379-402. https://doi.org/10.1177/0022002704263710

Boulding, Kenneth. 1989 The three faces of power. Newbury Park Sage. 
Bueno de Mesquita et al. 2003. The Logic of Political Survival. Cambridge: MIT Press

Cobertta, Renato, and Molly Melin. 2017. "Exploring the threshold between conflict management and joining in biased interventions". Journal of Conflict Resolution 20, no. 10 (July): 1-27. https://doi.org/10.1177\%2Fo022002717720754

Dawisha, Adeeb. 1978. "Syrian in Lebanon: Assad's Vietnam?” Foreign Policy, no. 33: $135-150$.

Deeb, Marius. 2003. Syria's terrorist war on Lebanon and the peace process. New York: Palgrave MacMillian

Doyle and Sambanis. 2000. "International Peacebuilding: A Theoretical and Quantitative Analysis". American Political Science Review 94, no. 4 (December): 779-801. DOI: $10.2307 / 2586208$

Elbadawi e Sambanis 2000. External Interventions and the Duration of Civil Wars, Working Paper. Washington, DC: World Bank

Encarnation et. al. The impact of concerned parties on the resolution of disputes. In Lindgren, Goran, Wallensteen, Peter e Kjell-Ake Nordquist (eds). 1990. Peace Processes in the Third World. Uppsala: Uppsala University. 42-96.

Favretto, Katja. 2009. "Should Peacemakers Take Sides? Major Power Mediation, Coercion and Bias". American Political Science Review 103, no. 2: 248-63. doi:10.1017/ S0003055409090236.

Fortna, Virginia. 2004. Peace Time: Cease-Fire Agreements and the Durability of Peace. Princeton: Princeton University Press

Gent, Stephen. 2007. "Strange Bedfellows: The Strategic Dynamics of Major Power Military Interventions". Journal of Politics 69, no. 4. https://doi.org/10.1111/j.1468 2508.2007.00609.x

Hinnebusch, Raymond. 1986. "Syrian policy in Lebanon and the Palestinians". Arab Studies Quarterly 8, no. 1 (July): 1-20. JSTOR

1998. "Pax-Syriana? The origins, causes and consequences of Syria's role in Lebanon". Mediterranean Politics 3, no. 1: 137-10. https://doi. org/10.1080/13629399808414644

Holl, Jane. 1993 “When War Doesn’t Work: Understanding the Relationship between the Battlefield and the Negotiating Table". In Licklider, Roy (eds). 1993. Stopping the Killing: How Civil Wars End. New York: NYU Press. (269-291) 
Hudson, Michael. 1978. "Palestinian factor in Lebanese civil war". Middle East Journal 32, no. 3 (Summer): 261-278. JSTOR

Kathman, Jacob. 2010. "Civil war contagion and neighboring interventions". International Studies Quarterly 54, no. 4 (December): 989-1012. https://doi.or$\mathrm{g} / 10.1111 / \mathrm{j} .1468-2478.2010 .00623 . \mathrm{x}$

2011. "Civil war diffusion and regional motivations for intervention". Journal of Conflict Resolution 56, no. 6 (July): 847-876. https://doi.or$\mathrm{g} / 10.1177 \% 2 \mathrm{~F} 0022002711408009$

Kydd, Andrew. 2003. "Which Side Are You On? Bias, Credibility, and Mediation", American Journal of Political Science 47, no. 4: 597-61. Doi 10.2307/3186121

Kim, Sang. 2015. "Third-party intervention in civil wars and the prospects for postwar development”. Journal of Peace Resolution 61, no. 3 (July): 1-28 https:// doi.org/10.1177\%2F0022002715590873

Lawson, Fred. 1984. "Syria's intervention in Lebanese civil war, 1976: a domestic conflict explanation”. International Organization 38, no. 3 (Summer): 451-480. https://doi.org/10.1017/So020818300026813

Lemke, Douglas e Patrick Regan. "Intervention as Influence." In Diel, Paul (eds). 2004. The Scourge of War: New Extensions on an Old Problem. Ann Arbor: University of Michigan Press. 145-68.

Lindsay, Dylan e Andrew Enterline. 2000. "Killing Time: The World Politics of Civil War Duration, 1820-1992”, International Studies Quarterly 44, no. 2: 615-642

Mason. David, Weingarten, Joseph e Patrick Fett. 1999. "Win, Lose, or Draw: Predicting the Outcome of Civil Wars", Political Research Quarterly 52, no. 2: 239268. https://doi.org/10.1177\%2F 106591299905200201

Mitton, John. 2017. "Rivalry intervention in civil conflicts: Afghanistan (IndiaPakistan), Angola (USSR-USA), and Lebanon (Israel-Syria)". Canadian Foreign Policy Journal 1 1, no. 1: 01-15. https://doi.org/10.1080/1 1926422.2017.1348957

O’Ballance, Edgar. 1998. Civil war in Lebanon, 1975-92. Hampshire: Palgrave MacMillan.

Ramsbotham, Oliver et al. 2005. Contemporary Conflict Resolution. Cambridge: Polity. 
. 1996. "Conditions of successful third-party intervention in intrastate conflicts”. Journal of Conflict Resolution 40, no. 2 (June): 336-359. https://doi.org/ $10.1177 \% 2$ Fo022002796040002006

Regan, Patrick. 2000. 'The Substitutability of US Policy Options in Internal Conflicts', Journal of Conflict Resolution 44, no. 1: 90-106

Regan, Patrick. 2002. "Third party interventions and the duration of intrastate conflicts". Journal of Conflict Resolution 46, no. 1 (February): 55-73. https://doi. org/10.1177\%2F0022002702046001004

Rosenau, James. 1969. "Intervention as a Scientific Concept.”. Journal of Conflict Resolution 13, no. 2: 149-71. https://doi.org/10.1177\%2F002200276901300201

Ross, Michael. 2004. "How Do Natural Resources Influence Civil War? Evidence from Thirteen Cases". International Organization 58, no. 1: 35-67. https://doi. org/10.1017/So02081830458102X

Sawyer et al. 2015. "The role of external support in civil war termination". Journal of Conflict Resolution 61, no. 6 (September): 1174-1202. https://doi.or$\mathrm{g} / 10.1177 \% 2$ FoO22002715600761

Seale, Patrick. 1998. Asad of Syria: the struggle for the Middle East. London: I. B. Tauris,

Suhrke, Astri \& Lela Garner Noble, eds, 1977. Ethnic Conflict in International Relations. New York: Praeger.

Thompson, Eric. 2002. "Will Syria Have to Withdraw from Lebanon?". Middle East Journal 56, no. 1 (Winter): 72-93. JSTOR

Walter, Barbara. 2002. Committing to Peace: The Successful Settlement of Civil Wars. Princeton: Princeton University Press

Weinberger, Naomi. 1986. Syrian intervention in Lebanon: the 1975-76 civil war. New York: Oxford University Press.

Yuen, Amy. 2009. "Target Concessions in the Shadow of Intervention”. Journal of Conflict Resolution 53: 745-93. https://doi.org/10.1177\%2F0022002709339046

Zartman, William, 1993. "The Unfinished Agenda: Negotiating Internal Conflicts". In Licklider, Roy (eds). Stopping the Killing: How Civil Wars End, 1993. New York: NYU Press (20-36). 


\section{NOTAS}

1. Em um típico comportamento de adesão, o agente interventor toma o lado de alguma das facções beligerantes ou junta-se a ela no combate armado. 


\section{A SÍRIA COMO ATOR NA GUERRA CIVIL LIBANESA: MOTIVAÇÕES E EFEITOS DA INTERVENÇÃO DE UMA TERCEIRA PARTE NA RESOLUÇÃO DE CONFLITOS}

\section{RESUMO}

Entre 1975 e 1991, o Líbano vivenciou uma sangrenta guerra civil, que vitimou aproximadamente cento e vinte mil pessoas. Produto das divisões sectárias em voga desde o período colonial, o conflito colocou cristãos e muçulmanos em confronto, além de ter a participação de terceiros com interesse regional. Apesar do caráter doméstico da guerra, dentre os atores regionais destaca-se a Síria. O comportamento de Damasco como terceira parte não foi homogêneo. Em algumas ocasiões, o governo sírio desempenhou a função de mediador, negociando tréguas entre as facções beligerantes. Em outras, interveio militarmente ou apoiou alguns grupos em detrimento de outros. Neste contexto, o presente artigo propõe-se a examinar o papel sírio na Guerra Civil Libanesa. O objetivo consiste em analisar essa atuação à luz da literatura de resolução de conflitos, em especial aquela que trata da intervenção de uma terceira parte no processo de resolução. Particularmente, será dada ênfase às motivações e aos efeitos da intervenção síria sobre a evolução e o término do conflito libanês. Os resultados demonstram que: a intervenção de uma terceira parte em um conflito doméstico é quase inevitável; sua ação é impelida por motivos diversos e contingentes; e que ela influencia a evolução desse tipo de beligerância.

Palavras-chave: Líbano; Guerra Civil; Síria; Resolução de Conflitos; Terceira Parte.

\section{ABSTRACT}

Between 1975 and 1991, Lebanon experienced a bloody civil war that killed approximately 120,000 people. Product of the sectarian divisions in vogue since the colonial period, the conflict put Christians and Muslims in confrontation, having also the participation of third parties in the regional geopolitical setting. Despite the domestic character of the war, among the regional actors, Syria stands out. Damascus's behavior as a third party had not been homogeneous. On some occasions, the Syrian government has played the role of mediator, negotiating a truce between the belligerent factions. In others, it intervened militarily or supported some groups over others. In this context, this article proposes to examine the Syrian role in the Lebanese Civil War. The objective is to analyze this action in the light of the conflict resolution literature, especially that dealing with the intervention of a third party in the resolution process. In particular, emphasis will be given to the motivations and effects of Syrian intervention on the evolution and end of the Lebanese conflict. The results demonstrate that: the intervention of a third party in a domestic conflict is almost inevitable; its action is impelled by diverse and contingent reasons; and that it influences the evolution of this kind of belligerence.

Keywords: Lebanon; Civil War; Syria; Conflict Resolution; Third Party. 